Now all this egregious contrast between human society, as well as the flora, on the one side, versus the other, of Southern Africa (excepting some details dependent on the soil and the prevailing direction of the wind) are due to the Indian Ocean imparting to the air on the east coast an invisible, yet most potent quality which the Atlantic does not confer on the western coast. Could there then be found a more expressive emblazon, suitable to the present day, for a cost of arms for one of the flourishing new Governments on the eastern side of South Africa, than a wet, and dry, bulb hygrometer pictured with both bulbs marking $85^{\circ} \mathrm{F}$., and with the surf of the Indian Ocean beating in the distance? May 29

C. Piazzi Smyth

\section{The Composition of the Edible Bird's-Nest}

As I have been much interested in the controversy concerning the composition of the edible bird's-nest, and particularly in the bearing of Mr. Green's investigations, which are given at length in your last issue (p. 8r), w ould you permit me to give the result of some observations I made on this subject in the Solomon Islands. It will be remembered that it was the association of these nests with a so-called "fungoid growth" in the caves of North Borneo that led Mr. Pryer to consider that he had found the source of the material of which the nests are made, a supposed discovery which led to the re-opening of the controversy (NATURE, vol. xxx. p. 271). This low plant-substance was determined by $\mathrm{Mr}$. George Murray to be the result of the growth of a microscopic alga, a species, probably new, of Glcocapsa (Proc. Zool. Soc., 1884 , p. 532).

In the Solomon Islands I was only able to obtain the edible nest in one locality (Oima Atoli) since the bird usually frequents inaccessible sea-caves and cliffs. The nests were of inferior quality, and were for the most part composed of fibrous materials derived from the vegetable drift (the husks of pandanus seeds especially). The gelatinous :ubstance thickly incrusted the interior of the nests, and attached them to the rock. The surface of a cliff in the vicinity of the cave frequented by the swifts was coated by a reddish gum-like growth, which proved on examination to be an aggregation of the cells of a protophytic alga about $\mathrm{r} / \mathbf{2 5 0 0}$ of an inch in size. Unfortunately my specimens of this growth have miscarried, but I feel assured that it is very similar to that observed by Mr. Pryer in the Borneo caves, samples of which, through the kindness of Mr. George Murray, I had the opportunity of seeing at the British Museum. A similar growth is commonly to be found coating the coral-limestone cliffs in this group. It may be seen in all stages, the older portions being dark-coloured and rather tough, and the fresher portions being, as Mr. Pryer aptly remarked, like half-melted gum tragacanth. There are but few cells in the fresh alga, the mass being apparently composed of cellular debris, immersed in a rather diffluent material, the whole somewhat resembling the third section given in Mr. Green's paper.

That the salivary glands are especially concerned in the production of the gelatinous nest-substance there can now be but little doubt, and the investigations of Mr. Green have established the nature of its composition; yet it is possible, and I make the suggestion with great diffidence, that a vegetable mucin, or a sub stance closely allied to this animal product, may be found in these low plant-growths.

95, Albert Street, N.W., May 29

H. B. GUPPY

\section{"Arithmetic for Schools"}

IN NATURE of May 20 (p. 5I) there appears a criticism of my "Arithmetic for Schools," in which your reviewer states :"In the purely arithmetical part of the book logical accuracy is attempted with considerable success. Want of grasp is much more evident in the part which deals with the applications. Then the division into subjects is strangely illogical, and slight inaccuracies of thought and language occur. Is it really the case, for example, that rate of interest (p. 18I) is totally independent of time?" These are very serious charges to make against a book of the kind, and ought not to be made without very good reacon. As your reviewer suggests the inferences (I) that the book is divided into parts, one of which contains the "pure arithmetic," and the other the "applied," and (2) that it is stated that rate of interest is totally independent of time, and as neither of these inferences has any foundation in fact, it seems only fair to myself that your reviewer should be asked to quote verbatim the other slight inaccuracies on which he bases his general statement.

Gonville and Caius College, May 24 JoHN B. Lock

\section{SUNSPOTS AND PRICES OF INDIAN FOOD- GRAINS}

IN the volume of the Bombay Gazetteer which deals with the province of Kathiawar, there is at page 217 a long list of prices of the principal food-grains at Bhavnagar. The list contains, along with other information, the price of Indian millet for nearly every year from 1783 to 1882 . This series of figures is long enough to afford the means of testing whether there is any tendency, in India, for times of scarcity, and consequent dearness of food, to recur after more or less regular intervals of years.

Ever since the discovery by Schwabe of the periodicity of the sunspots, and the further discovery by Sabine of the same periodicity in the variations of the earth's magnetism, there has been a growing belief in the minds of scientific men that the varying condition of the sun exerts a far greater influence on terrestrial affairs than is usually thought at all probable, and various investigators have traced, with more or less definiteness, a periodicity of eleven years-coinciding with that of the sunspots-in the variations of the rainfall, in those of the temperature and pressure of the atmosphere, and in the frequency of storms, \&c. The late Prof. Stanley Jevons went so far as to express the opinion that even trade depressions are the remote effects of corresponding variations in the condition of the sun.

I am not aware that any attempt has hitherto been made to trace out any direct connection between the variations of prices in India and solar phenomena. The apparent hopelessness of the task has probably acted as a sufficient deterrent, for although it may be reasonable to suppose that solar variations influence the rainfall and other purely physical phenomena, yet it is well known that there are many causes of variation of price which cannot, with any show of reason, be attributed directly to the sun. Such, for instance, are wars, the gradual increase of the population, variations in the quantity of money in use, changes in the total volume of trade, \&c. These circumstances complicate the problem very much, but it does not necessarily follow that it is hopeless to attempt to trace the possible influence of solar periodicity on the prices; for there are statistical methods by which most of the disturbing influences can be approximately, if not entirely, eliminated. Indeed, when these methods of elimination have been applied, it may be found that the solar periodicity is more decidedly traceable in the prices than in the rainfall : for, in the one case, the produce of every field exercises its due share of influence in determining the price ; while, in the other case, the quantity of rain actually measured is but an infinitesimal portion of the whole quantity which falls, and may therefore very imperfectly represent the total rainfall over the whole of a district.

In considering a price in relation to the causes of variation to which it is subject, it may be thought of as divided into portions, each portion being assigned to its own particular cause. What is wanted here is to separate as distinctly as possible that portion which may be due to the variation of the influence of the sun from all the rest. But before any satisfactory attempt can be made to distinguish that portion of the price variation which may be due to variation of solar influence from the portion due to the average amount of solar influence and to other causes, it is necessary to adopt some standard of comparison which may reasonably be supposed free from solar effects of a periodically variable nature. Now as the physical state of the sun is known to go through a complete cycle of changes in a period of almost exactly eleven years, the average price for any consecutive eleven years 
will be affected by the average amount of solar influence, and the difference between this average price and the actual price for the middle year of the eleven will be affected by the difference between the average condition of the sun and its actual condition in that middle year. This difference of price may also include the effects of other extraneous and non-periodic causes. Eleven years after the middle year just mentioned the sun will again be in its former condition, and a similar price difference for that year may be calculated. The same process may be carried on to the twenty-second, thirty-third, \&c., years, and it will then produce a series of price differences equally affected by equal periodical solar influence. Nonperiodic causes will, however, sometimes tend to unduly raise these price differences, sometimes to depress them, but on the average such disturbances will, in a long series of years, tend to balance each other, leaving the periodical portion of the solar influence outstanding. If, for instance, the years for which the calculations of the price differences have been made are those in which the sunspots are at a maximum, the average price difference will show how much prices tend to be raised or depressed by that condition of the sun which produces most spots. A similar series of calculations may be made for the years in which the spots are at a minimum, also for the intermediate years when the spots are increasing, and for those years when the spots are decreasing. A set of eleven average price differences, one for each year of the sunspot cycle of eleven years, will thus be obtained, and"if, on arranging them in consecutive order, they show that prices are, on the average, decidedly high in those years when there are few sunspots, and decidedly low when the sunspots are numerous, or if they show any other decided and systematic variation in the sunspot period, the conclusion will be that the sunspot cycle does really affect the prices. If, on the other hand, the prices do not change in any systematic manner in the different years of the sunspot cycle, the conclusion will be against the hypothesis of a periodical variation of the prices corresponding to the periodical variation of the sunspots.

There is one point of view from which this method of taking differences is open to some objection. Suppose, merely for the sake of illustration, that the average price of millet throughout some particular sunspot period of eleven years is 50 pounds for a rupee, but that in the year of maximum sunspots the solar influence is such as to double the crop and lower the money price or raise the quantity price proportionately, that is, to roo pounds for a rupee. The price difference for that year would be 50. If, however, by reason, say, of a more plentiful supply of money, the average price of millet for the whole of another sunspot period of eleven years is only 25 pounds for a rupee, and the crop in the year of maximum sunspots is, through solar influence, similarly doubled, the quantity price would only rise to 50 pounds, and the price difference would be only 25 , although the solar influence, which is supposed to have produced the change, is the same as before. The difference between the two results would be due simply to the more plentiful supply of money, not at all to a difference of solar influence. This shows that it is needful to adopt some modification of the method, which will allow for gradual changes in the amount of money in use, and other similar causes of alteration of price. Such a modification will be made if, instead of taking price differences, the actual price of the middle year of the eleven is expressed as a percentage of the average price. Expressed in this way, the percentage for the year of maximum sunspots in each of the above examples would be 200 , that is to say, in each case the number of pounds for a rupee would be 100 per cent. greater than the average number.

Table I. contains the Bhavnagar price list expressed in the percentage form in the manner just described. In the original table the prices are expressed in pounds for a rupee. If, therefore, the number for any year in Table I. is 125 , it means that the number of pounds of grain for a rupee is 25 per cent. greater than the corresponding eleven-yearly average ; and if the number is 75 it means that the number of pounds for a rupee is 25 per cent. less. In other words the excess above or the defect below roo shows how much per cent. the number of pounds for a rupee is above or below the corresponding eleven-yearly average.

TABLE I.-Percentages, Bhavnagar.

\begin{tabular}{|c|c|c|c|c|c|c|c|c|c|c|c|}
\hline Years. & $x$ & 2 & 3 & 4 & 5 & 6 & 7 & 8 & 9 & 10 & II \\
\hline 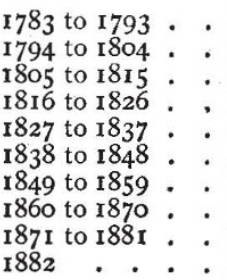 & $\begin{array}{r}57 \\
66 \\
70 \\
118 \\
141 \\
9 \mathrm{r} \\
132 \\
103 \\
93 \\
100\end{array}$ & $\begin{array}{r}66 \\
69 \\
117 \\
159 \\
98 \\
58 \\
96 \\
100 \\
93\end{array}$ & $\begin{array}{r}56 \\
140 \\
97 \\
162 \\
137 \\
100 \\
96 \\
103 \\
133\end{array}$ & $\begin{array}{r}143 \\
\text { I6 } 3 \\
\text { I39 } \\
\text { IO3 } \\
96 \\
92 \\
\text { IO2 } \\
86 \\
\text { I } 26\end{array}$ & $\begin{array}{r}\mathbf{1} 57 \\
\mathbf{1} 45 \\
\mathbf{2} 24 \\
68 \\
121 \\
8 \mathbf{1} \\
104 \\
52 \\
126\end{array}$ & 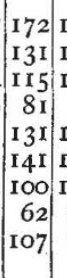 & \begin{tabular}{|r|r}
185 & $\mathrm{x}$ \\
108 \\
106 \\
78 \\
135 \\
$\mathrm{r} 64$ \\
106 \\
87 \\
87 \\
89
\end{tabular} & \begin{tabular}{r|r|}
104 \\
82 \\
78 \\
III \\
71 \\
93 \\
912 \\
I 2 \\
rO5 \\
75 & 1 \\
75 & 1
\end{tabular} & \begin{tabular}{r|}
24 \\
78 \\
38 \\
71 \\
78 \\
86 \\
109 \\
104 \\
$7 \mathrm{I}$
\end{tabular} & $\begin{array}{r}60 \\
75 \\
69 \\
5 \mathrm{I} \\
79 \\
\mathrm{I} 07 \\
84 \\
92 \\
89\end{array}$ & $\begin{array}{r}6 \mathrm{I} \\
63 \\
85 \\
74 \\
8 \mathrm{I} \\
66 \\
\mathrm{I} 22 \\
84 \\
\mathrm{I} 18\end{array}$ \\
\hline $\begin{array}{l}\text { Means, including } \\
\text { I } 863 \text { to } \mathbf{1} 866 \\
\text { Means, excluding } \\
\text { I863 to } 1866 \text {. } \\
\text { Smoothed means. }\end{array}$ & $\begin{array}{l}97 \\
93\end{array}$ & $\begin{array}{r}95 \\
100\end{array}$ & $\left|\begin{array}{lll}1 & 1 & 4 \\
1 & 1 & 1\end{array}\right|$ & $\mid \begin{array}{l}120 \\
11\end{array}$ & $\mid \begin{array}{ll}1 & 1 \\
1 & 1\end{array}$ & $\begin{array}{l}122 \\
120\end{array}$ & $\left|\begin{array}{ll}1 & 2 \\
1 & 1 \\
1\end{array}\right|$ & $\begin{array}{l}92 \\
94\end{array}$ & $\begin{array}{l}73 \\
79\end{array}$ & $\begin{array}{l}78 \\
78 \\
78\end{array}$ & $\begin{array}{l}84 \\
86\end{array}$ \\
\hline
\end{tabular}

The numbers of Table I. are arranged in lines of eleven numbers each, so that the numbers occurring at equal intervals of eleven years, beginning with 1783 , all fall in the first column, those occurring at equal intervals beginning with 1784 , all fall in the second column, and so on. Now if there is any decided tendency for high or low prices to recur at more or less regular intervals of about eleven years, the great majority of the high prices should be found in a few contiguous columns in one part of the table, and the great majority of the low prices in a few contiguous columns in another part of the table. An examination of the numbers of Table $\mathrm{I}$. shows that this is the case, for in columns 9, 10, and II, no less than twentytwo out of the twenty-seven numbers are below Ioo, and only five of them are above IOo; while in columns 3 to 7 the great majority of the numbers are above 100 .

The average results are given at the foot of the table. They show that there is a decided tendency for years of high and low prices to recur, with some regularity, in a period of eleven years, five consecutive years being good years, when money prices are below the average ; and the six following years being bad years, when money prices are above the average. The years which give the highest average money price, or the smallest number of pounds for a rupee, are those in column 9. The average number of pounds for a rupee in those years is 27 per cent. below the eleven-yearly average. The years which give the lowest average money prices are those in columns 4,6 , and 7. The average number of pounds for a rupee in those years is about 17 per cent. greater than the elevenyearly average. There is thus an average difference of 44 per cent. between the years of low prices and those of high prices. This percentage difference would have been considerably greater if the prices had been reckoned in rupees for a fixed quantity of grain, instead of in pounds of grain for a rupee. To show that this is the case it is only necessary to convert the three prices II7, 100, and 73 regarded as pounds for a rupee, into their corresponding rupee prices, that is to say, into the number of rupees which would in each case be required to purchase 100 pounds. These are $0.85, I^{\circ} \circ 0$, and $I^{\prime} 37$ respectively, 
giving a difference between the highest and lowest of $0^{\circ} 52$, or no less than 52 per cent. of the average price, which is 8 per cent. more than the corresponding difference in the pound prices. Although this illustration by no means exhausts the question of the difference between quantity prices and money prices, it suffices for the purpose of guarding against the erroneous supposition that results worked out in quantity prices are directly applicable to money prices.

Having now found such remarkable evidence of regularly recurring periodical variations of the price of the staple food-grain at Bhavnagar, amounting on the average to more than 50 per cent. of the average money price, it seems desirable to inquire whether similar variations of price have taken place from year to year in other districts. For this purpose I have selected from the various volumes of the Bombay Gazetteer all those price lists which extend over periods of fifty years or more. These are for the districts of Ahmedabad, Kaira, Surat, Khandesh, Poona, Bijapur, Dharwar, Belgaum, and Kanara, and to these 1 have added Madras, for which station a long price list is given in the Report of the Indian Famine Commission.

The best way of testing whether any considerable portion of the variations of price in these districts can be regarded as regularly recurrent in a period of eleven years, corresponding to that of the sunspots, is to calculate the average eleven-yearly variation by the method already applied to the Bhavnagar prices. These calculations have been made. The results are entered in Table II. The corresponding average sunspot variation is also given.

TABLE II.

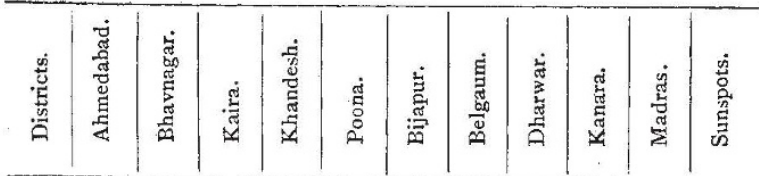

\begin{tabular}{|c|c|c|c|c|c|c|c|c|c|c|c|}
\hline Years. & $\begin{array}{l}18 \mathbf{r}_{3} \\
\text { to } \\
1877\end{array}$ & $\begin{array}{c}1783 \\
\text { to } \\
1882\end{array}$ & $\begin{array}{l}1790 \\
\text { to } \\
1882\end{array}$ & $\begin{array}{c}\mathrm{r} 825 \\
\text { to } \\
\mathrm{r} 879\end{array}$ & $\begin{array}{c}r 8 c 9 \\
\text { to } \\
\mathbf{r} 882\end{array}$ & $\begin{array}{c}r 823 \\
\text { to } \\
3882\end{array}$ & $\begin{array}{c}18.24 \\
\text { to } \\
\text { I882 }\end{array}$ & $\begin{array}{c}x 823 \\
\text { to } \\
\times 88_{3}\end{array}$ & $\begin{array}{c}x 824 \\
\text { to } \\
x 882\end{array}$ & $\begin{array}{c}18 \mathrm{rr} \\
\mathrm{t} \\
\mathrm{r} 877\end{array}$ & $\begin{array}{l}x 810 \\
\text { to } \\
x 875\end{array}$ \\
\hline & 9I & 97 & 99 & IOI & I19 & 124 & I I 3 & $\begin{array}{l}1 \\
5\end{array}$ & 95 & II 6 & 84.4 \\
\hline 2 & IOr & 95 & 101 & 89 & 99 & Ior & 91 & 102 & 102 & 109 & $72 \cdot 1$ \\
\hline 3 & 120 & II 4 & $1 \times 5$ & 121 & I 13 & 102 & I I I & 98 & II 2 & IIO & $5^{8} \cdot 4$ \\
\hline & IIO & 120 & 110 & 123 & 113 & 127 & 108 & II 2 & 114 & 123 & $45^{\circ} \circ$ \\
\hline & 104 & I16 & I I9 & $1 \times 8$ & 108 & 114 & 117 & 106 & 115 & II 5 & 32.0 \\
\hline & 126 & 122 & 116 & 126 & 102 & 80 & 106 & 120 & 105 & 89 & 19.6 \\
\hline & IIO & $12 \mathrm{I}$ & 95 & 78 & 75 & 67 & 78 & 69 & 103 & 83 & 94 \\
\hline & & 92 & 75 & 83 & 81 & 88 & 106 & 92 & 93 & 75 & I 2.2 \\
\hline 9 & & 7 & 76 & 83 & 89 & IOI & 92 & 120 & 93 & 77 & $33^{\circ} 2$ \\
\hline & 73 & & 87 & 75 & $8 \mathrm{I}$ & I I I & 103 & I1 5 & 88 & 87 & $64^{\circ} 0$ \\
\hline & & & 105 & 10. & I 26 & I 12 & 103 & 100 & 95 & 113 & $92 \cdot 3$ \\
\hline
\end{tabular}

In calculating the average sunspot variation the sunspot numbers before I 8 I I have been excluded, partly because they are very much less reliable than the numbers for the later years, from lack of continuous observations, partly because the mean variation for the later years will be more directly comparable with the price variations, which, except in two cases, are deduced from the data of the years following 1810 . In calculating the average eleven-yearly price variations the data for the years 1863 to 1866 have been excluded, because it is known that in those years prices were very much raised by the influence of the American war.

There is some irregularity in the eleven-yearly price variations (especially in those for Dharwar and Belgaum) which can hardly be attributed directly to the solar influence. The best way of removing this irregularity will be to take the means of each consecutive pair of the eleven

\footnotetext{
I The year $187 \mathrm{I}$ is taken as the first year of the sunspot cycle of eleven
}

\section{PRICES OF FOOD GRAINS IN INDIA RECKONED IN POUNDS FOR A RUPEE.}

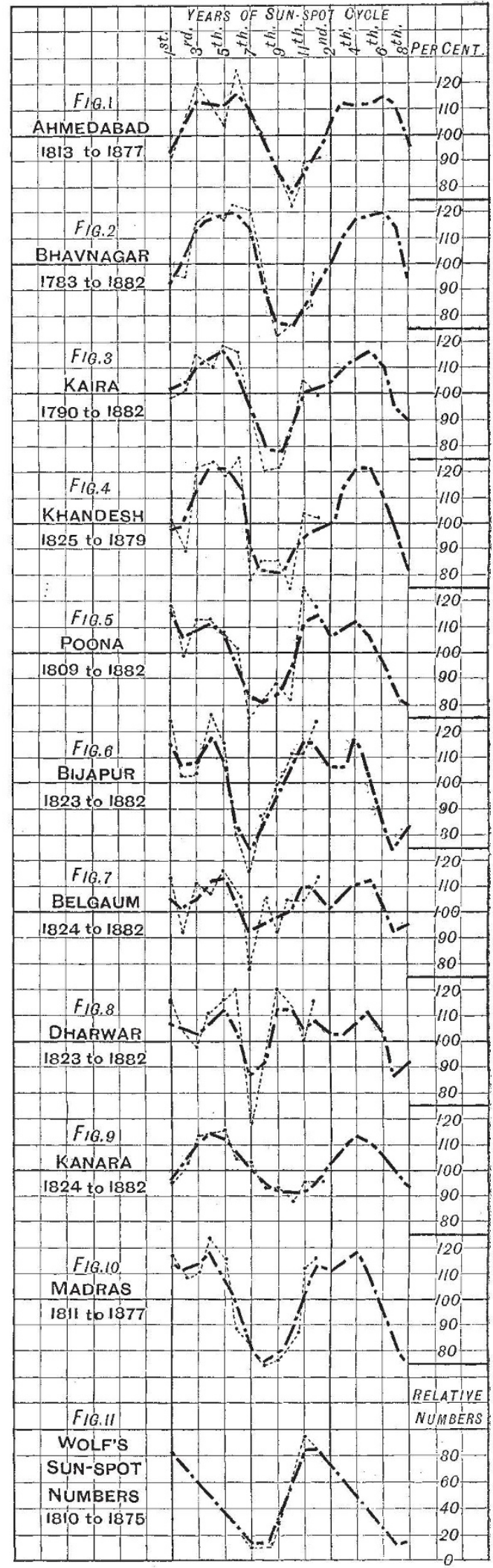


average numbers which constitute the eleven-yearly price variation, and to repeat the process on the new means. This has been done, and the results are given in Table III,

TABLE III.

\begin{tabular}{|c|c|c|c|c|c|c|c|c|c|c|c|}
\hline 鰙 & 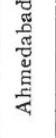 & 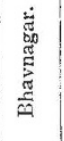 & 氙 & 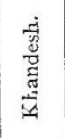 & 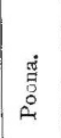 & 言 & 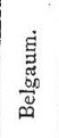 & 苞 & 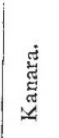 & 常 & ڤี \\
\hline Years & $\begin{array}{c}18 r_{3} \\
\text { to } \\
1877\end{array}$ & $\begin{array}{c}1783 \\
\text { to } \\
\mathbf{1} 882\end{array}$ & $\begin{array}{c}1790 \\
\text { to } \\
\times 882\end{array}$ & $\begin{array}{c}1825 \\
\text { to } \\
1879\end{array}$ & $\begin{array}{c}x 809 \\
\text { to } \\
\mathbf{1} 88 \boldsymbol{z}\end{array}$ & $\begin{array}{c}1823 \\
\text { to } \\
1882\end{array}$ & $\begin{array}{c}1824 \\
\text { to } \\
1882\end{array}$ & $\begin{array}{c}1823 \\
\text { to } \\
188_{3}\end{array}$ & $\begin{array}{c}1824 \\
\text { to } \\
1882\end{array}$ & $\begin{array}{c}18 \mathrm{rr} \\
\text { to } \\
8877\end{array}$ & \\
\hline & 93 & 93 & IOI & 99 & I 6 & I I 5 & 105 & 108 & 97 & I I 3 & \\
\hline 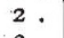 & IO 3 & 100 & IO4 & IOO & I07 & 107 & IOI & IO4 & 103 & II I & \\
\hline 3 & II 3 & I I I I & I 10 & $\mathrm{I} 13$ & I09 & I08 & 105 & 102 & IIO & 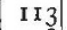 & \\
\hline A & I I I & I I 7 & 113 & 121 & 112 & 177 & III & 107 & II 4 & I I 8 & \\
\hline & I I I I & 118 & $1 \times 6$ & $12 \mathrm{I}$ & 108 & rog & 112 & I I I & 112 & I IO & \\
\hline & I 66 & 120 & IXI & II 2 & 97 & 85 & 102 & 104 & 107 & y. & \\
\hline & III & II 4 & 95 & $9 \mathrm{I}$ & 3 & 75 & 92 & 87 & IOI & 82 & \\
\hline & 97 & 94 & 0 & 82 & $8 \mathrm{I}$ & 86 & 95 & 93 & 95 & 77 & \\
\hline & 84 & 79 & 78 & $8 \mathbf{I}$ & 85 & 100 & 98 & I I 2 & 92 & 7 & \\
\hline & 79 & 78 & 89 & 84 & 94 & I09 & 100 & II 2 & $9^{I}$ & $9 \mathbf{I}$ & \\
\hline & 85 & 86 & 99 & 96 & I I 3 & 115 & 105 & 107 & 93 & I07 & \\
\hline
\end{tabular}

These smoothed results are graphically represented by the dots connected with black lines in Figs. I to ro. To show the effect of the smoothing process the original unsmoothed numbers, viz. those of Table II., are graphically exhibited over the smoothed curves by the dots joined with faint dotted lines. It will be seen from these figures that the application of the smoothing process has got rid of almost all the irregularity. At the same time it has somewhat unduly reduced the range of the elevenyearly variations. The amount of this reduction may be roughly estimated by applying the same smoothing process to the eleven average sunspot numbers given in the last column of Table II. This has been done in the last column of Table III. The results are curved in Fig. I I. The range of the original unsmoothed numbers is $82^{\circ}$, that of the resulting smoothed numbers is 70.6 ; that is to say, the range of the smoothed numbers would have to be increased by 17 per cent. of itself to obtain the full range of the original numbers. From this it may be inferred that the range of each of the smoothed elevenyearly price variations represented by Figs. I to Io is too small, and should be increased by about I7 per cent. of itself to obtain the full range of the variation. On the other hand, the extreme range of the unsmoothed numbers will probably be somewhat too great in most cases, because the data do not extend over a sufficient number of years to eliminate completely the effects of casual fluctuations. The true mean range of the variation caused by solar influence will therefore probably lie somewhere between the range of the unsmoothed numbers and that of the smoothed numbers. The ranges of both the unsmoothed and the smoothed variations are shown below for each district. The range of each smoothed variation increased by 17 per cent. of itself is also given.

\begin{tabular}{|c|c|c|c|c|c|c|c|c|c|c|}
\hline & 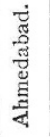 & 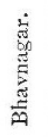 & 营 & 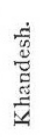 & $\begin{array}{l}\text { हึँ } \\
\text { ह̊ } \\
\text { م }\end{array}$ & 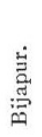 & 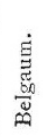 & 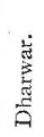 & 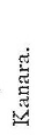 & 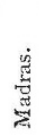 \\
\hline Unsmoothed & 53 & 49 & 44 & $5 \mathrm{I}$ & $5^{\mathrm{I}}$ & 60 & 39 & $5^{I}$ & 27 & 48 \\
\hline Smoothed . & 37 & 42 & $3^{8}$ & 40 & 35 & 42 & 20 & 25 & 23 & $4 \mathrm{I}$ \\
\hline Smoothed, plus & & & & & & & & & & \\
\hline I7 per cent. & 43 & 49 & 44 & 47 & $4^{\mathrm{I}}$ & 49 & 23 & 29 & 27 & 48 \\
\hline
\end{tabular}

Now these results reveal the remarkable fact that, amid all the apparently irregular fluctuations of the yearly prices, there is in every one of the ten districts a periodical rise and fall of prices once every eleven years, corresponding to the regular variation which takes place in the number of the sunspots during the same period. They also show that in seven out of the ten districts the range of the eleven-yearly variation of prices lies between 40 and 50 per cent. of the average price, and that in the remaining three districts the range lies between 20 and 30 per cent. The ranges are greatest in those districts where scarcity and famine are most frequent, smallest in those which enjoy the greatest immunity in these respects. In Bijapur and the neighbouring districts of Belgaum and Dharwar the highest prices occur in the year of minimum sunspots; in Madras, Poona, and Khandesh a year or two later; in Kanara, Kaira, and Bhavnagar two or three years later; and in Ahmedabad three years later. The lowest prices occur in all the districts from three to five years after the year of maximum sunspots, that is to say, three years after at the southern stations; four or five years after at the northern. Bijapur and Poona are the first to show a very decided rise of prices, and this rise takes place in the year preceding the year of minimum sunspots. At all the other stations a very decided rise takes place a year or two later.

From what has been said it follows that the intervals of time between the year of minimum sunspots and the years of highest prices are less than the intervals between the year of maximum sunspots and the years of lowest prices. This shows that the eleven-yearly price variations do not exactly correspond to the eleven-yearly sunspot variation. The reason may be that on the occurrence of scarcity prices rise very rapidly, while on the return of a season of plenty they fall much more slowly, because the reserve stocks of grain consumed during a period of scarcity cannot be fully replaced until good crops for several successive years have been secured. If it were possible to obtain data showing the actual out-turn of the crops of each year, it would perhaps be found that the eleven-yearly variations calculated therefrom would correspond to the sunspot variation even more closely than the price variations correspond to it.

In estimating the significance of these eleven-yearly variations it must be remembered that quantity prices, not money prices, have been dealt with, and that the corresponding money prices would show a much greater percentage rise in dear times, and a less percentage fall in cheap times than are shown by the quantity prices. Indeed, to a person accustomed to thinking of money prices the quantity prices are apt to be very misleading if the difference is not constantly borne in mind, as may be seen from the consideration that if the quantity price, that is, the number of pounds for a rupee, becomes 50 per cent. less, that is dearer, than usual, the corresponding money price is 100 per cent. higher; while if the quantity price becomes 50 per cent. more, that is cheaper, the corresponding money price is only 33 per cent. lower. From a money point of view, therefore, a fall of 50 per cent. in the number of pounds for a rupee is much more serious than it seems to be, while a rise of 50 per cent. in that number is less advantageous than might at first sight be supposed. For financial purposes it would probably be best to convert the quantity prices at the beginning into their money equivalents, because it is impossible accurately to convert results (such as averages and the like) worked out in quantity prices into corresponding results, expressed in money prices. ${ }^{1}$ Such conversions always give a too favourable appearance as regards cheap-

${ }^{x}$ For purely scientific purposes it would perhaps be best to work with the logarithms of the original prices, instead of with the prices themselves, regartless as to whether the prices are expressed in pounds for a rupee, or in rupees for a fixed quantity of grain. It would then be possible to pass directly from the results of one system to those of the other, without having to go through the labour of recalculation. 
ness of food in times of plenty; and make the dearness of food in times of scarcity appear far less serious than it really is.

One of the most important practical results of this investigation probably is, that it affords a certain amount of power to predict the variations of prices in the coming sunspot cycle. Of course, until all those fluctuations which appear at present to be subject to no law have been explained and reduced to order, if ever that should be possible, exact prediction in any individual case is altogether out of the question, but as there is a regularly recurring eleven-yearly wave of prices running through the irregular fluctuations and following the sunspot wave in the manner defined by the curves, it is possible to form an estimate of the general level of prices in the different years of the coming sunspot cycle. There is thus some reason for believing that the present period of low prices following the last maximum of sunspots, which appears to have occurred about the end of 1882 or early in 1883 , will not last very much longer, a brisk rise of prices being due in the Deccan and in Madras five years after the sunspot maxinum, that is, in 1887 or I 888 , and in more northern districts a year or two later.

This estimate will, of course, be subject to modification if it should be found that the sunspot curve is declining towards its minimum more or less rapidly than usual. The last period of sunspots appears to have been somewhat longer than the average, that is, about twelve years from the maximum of 1870 to that of 1882 , instead of the normal length of almost exactly eleven years; and the coming minimum may possibly follow the last maximum more quickly than usual. Fortunately, the sunspot observations are not the only indicators of this cosmical periodicity, for, as I have shown in a paper communicated to the Royal Society in 1884 , the magnetic observations recorded at the Colaba Observatory afford far smoother and more definite indications of this periodicity than the sunspot observations ; and, what is even more important, the eleven-yearly magnetic variation precedes the sunspot variation by almost exactly six months, so that the magnetic indications are given half a year earlier than those of the sunspots.

Bombay, April 1886

\section{THE PHYSICAL APPEARANCE OF MARS} $I N \mathbf{I} 886$

A SERIES of observations of Mars were obtained here in March and April last with a ro-inch silveron-glass reflector by With of Hereford. The powers employed were 252 and 475 , but I found no advantage from the latter, which seemed too high for the purpose. As a rule a single lens magnifying 252 was amply sufficient, though there were several occasions when a power of about 350 would have been a decided acquisition.

The planet came to opposition on March 6, but during the first three weeks of March we had intense frosts, and it was not feasible to commence observations until towards the end of that month. The opposition magnitude of Mars was only $16^{\prime \prime} \cdot 6$, so that as regards apparent diameter the planet was far from being favourably placed. At the opposition of 1877 the diameter was no less than $29^{\prime \prime} 5$. But at the recent opposition the north hemisphere of the planet (which has not hitherto been so thoroughly examined as the south hemisphere, and does not exhibit so many striking features) was well presented for observation, the latitude of the centre of the disk being about $22^{\circ} \mathrm{N}$. in March and April.

The markings seen were both numerous and diversified. There is evidently a mass of detail on the planet, which is, however, most difficult to trace out in reliable characters. Many faint lineaments reach the eye with sufficient distinctness to prove their existence, but they cannot be held steadily enough or with that perspicuity to allow of the delineation of their outlines, or to enable their relative positions to be correctly assigned. Only the more pronounced features can be drawn satisfactorily. The small diameter of Mars during the recent observations has in a great measure induced this uncertainty as to the physical aspect of the disk. Another cause is found in the rarity of really good telescopic images. Not only must the atmosphere be peculiarly favourable to sharp definition, but there must be an absence of wind. A complicated system of markings cannot be made out under the influence of annoying vibrations. Moreover, this planet, considered as a telescopic object, is far less satisfactory than either Jupiter or Saturn, and this circumstance, with the other drawbacks alluded to, have given rise to that uncertainty, and to many of the discordances, in regard to the visible markings observed on his surface.

My intention in the present paper is merely to describe general results, as a particular description would scarcely be intelligible without drawings. Between March 23 and April 30 the planet was examined on twenty-one evenings, and a considerable number of sketches were completed. During the period mentioned the weather afforded an unusual number of clear nights, and whenever the seeing was fairly good the visible features were carefully noted, the results being afterwards compared with each other and with former work in the same direction. My drawings correspond very closely amongst themselves, and there is a fair agreement in the main features with those depicted on the charts of Green, Schiaparelli, Knobel, and others. I have also compared them with the views given in Terby's work on Mars and with Boeddicker's drawings of I88I and I 884 (with Lord Rosse's 3-foot reflector) published in the scientific Transactions of the Royal Dublin Society, and find in many instances a substantial confirmation. Some of the differences are larger than would have been considered probable, but experience has taught us that it is useless to expect uniformity in delineations of planetary details.

During the five weeks over which my observations extended I saw no conclusive evidences of physical changes in any of the markings. But the period was too limited, and the circumstances affecting the review altogether too unfavourable, to enable me to speak definitely on this point. The slight differences apparent amongst my drawings are merely such as were occasioned by changes in local atmospheric conditions. On a bad night faint markings, previously distinguished, would appear obliterated, and on thoroughly good nights I saw delicate appearances which were utterly beyond reach on less auspicious occasions. I am convinced that these changes in the character of the seeing, exercise great influence on the distinguishable features of a planet ; more so, in fact, than observers usually concede. Inferences of real change are sometimes hastily adopted in consequence, but they can only be substantiated after the most searching examination and the most convincing proofs.

The exterior edges of many of the well-defined seas on Mars are very brilliant, and their boundaries very definite. These brilliant outlying borders remind one of the light areas often abutting on the dark spots of Jupiter, only in the case of Mars they are more extensive, more permanent, and altogether dissimilar in form. I may instance a particular case of this bright bordering in the immediate region east of the Kaiser Sea on Mars. On several occasions this was so striking as to vie with the bright patch about the north pole. This shimmering extends several degrees east of the dark outline of the sea, but is limited by a faint and irregularly-condensed marking extending northwards, with an inclination east, from the knot in longitude $290^{\circ}$ just east of the north extremity of the Kaiser Sea as figured in Mr. Green's chart. This marking runs over a considerable tract, and its east extension underlies Davies' forked bay and Burton Bay, to both of which it is connected by faint ligaments of shade, 